\title{
Land cover mapping in cropland dominated area using information on vegetation phenology and multi-seasonal Landsat 8 images
}

\author{
Slim Mtibaa ${ }^{1} \cdot$ Mitsuteru Irie $^{2}$
}

Received: 1 April 2016/Accepted: 23 September 2016/Published online: 6 October 2016

(C) Springer International Publishing Switzerland 2016

\begin{abstract}
Information about land cover is required for economic, agricultural and environmental policy making. Therefore, reliable up-to-date information is always called upon. In this study, we developed a new approach for land cover mapping based on the information of vegetation phenology. The main objective of this approach was to generate a land cover map of large cropland dominated area with high classification accuracy. Our approach consisted of two steps: first, we divided the study area into three land use groups depending on the phenology trend of cereals. Second, we applied a supervised classification for each group using the Maximum Likelihood Classifier and multi-date satellite images. Recent multi-temporal Landsat 8 images and field survey data were used for the classification process. To assess the robustness of this approach, a conventional supervised classification was performed using single date and multi-date images. Results indicated that the proposed approach is able to discriminate between different land cover types which have a similar spectral reflectance such as cereals, vegetables and pasture with high accuracy. The accuracy assessment showed very promising results with an overall accuracy of $86 \%$ and a Kappa of 0.85 (good agreement) as compared to the single date $(54-55 \%)$ and the multi-date approach $(78 \%)$. Indeed, the application of this method provides accurate information for ecologists, hydrologists and the land
\end{abstract}

Slim Mtibaa

slim.mtibaa@th3pf.com

1 Graduate School of Life and Environmental Sciences, University of Tsukuba, 1-1-1 Tennodai, Tsukuba City, Ibaraki 305-8577, Japan

2 Faculty of Engineering, University of Miyazaki, 1-1 Kibanadainishi, Miyazaki-shi, Miyazaki, Japan development decision-makers. It can also improve the accuracy of environmental models that require high resolution land cover maps as input data.

Keywords Land cover mapping · Landsat 8 - Cropland dominated area $\cdot$ Vegetation phenology $\cdot$ High accuracy

\section{Introduction}

Land cover is the observed (bio) physical cover of the earth's surface [13]. Information about its spatial distribution is often a required input for many hydrological, climate and ecological models that aim to manage natural resources and assist decision-making face to environmental issues. Field surveys, literature review, map interpretation and collateral and ancillary data analyses are the traditional approaches for land cover mapping. However, they are not effective because they are time consuming, date lagged and often too expensive [82]. Over the past decades, new computer assisted methods based on remote sensing technologies, pattern recognition algorithms and geographic information systems (GIS) have been developed for land cover mapping and change monitoring [60]. Two types of methods can be distinguished: conventional and improved. The common conventional methods are the unsupervised and supervised classifications. Unsupervised classification is often used in thematic mapping because it is easy to apply and available in image processing software packages [39]. This method aims at classifying pixels according to their reflectance properties using clustering algorithms such as K-means and ISODATA. Moreover, derived clusters are assigned by the user. However, in the supervised classification method, different land cover classes should be defined in advance. Properties of these classes are 
learned from ground truth data (training samples). Then, pixels are classified according to their probability to belong to one of these classes based on statistical algorithms such as Maximum Likelihood or Minimum Distance algorithms.

Despite advances in remote sensing technologies, conventional image classification methods are still unable to produce land cover maps with high accuracy. Many researchers have developed improved methods to increase the classification accuracy $[8,9,14,18,27,29,66,69,71,72] . \mathrm{Lu}$ and Weng [47] reviewed these methods and concluded that per-field or object oriented classification algorithms outperform perpixel classifiers; methods based on a combination of spectral and texture information can reduce the impact of shadow resulting from topography, vegetation stand structures and wind spectral variation within the land cover classes; and nonparametric classifiers such as neural network, decision tree classifiers and knowledge-based classification are suitable for multisource data classification. Other researchers have developed hybrid methods that incorporate the advantages of different classification methods. Keuchel et al. [37] found that after the application of unsupervised classification for classifying the training samples into different subclasses, Maximum Likelihood Classifier (MLC), iterated conditional modes and support vector machine (SVM) methods gave satisfactory results with a statistical overall accuracy of about $90 \%$. Lo and Choi [45] found that the application of supervised fuzzy classification, after extracting homogenous clusters derived from an unsupervised classification, improved the classification accuracy up to $91.5 \%$. Thapa and Murayama [73] developed a GIS post processing approach taking into consideration the advantages of three different approaches (unsupervised, supervised and fuzzy supervised) to produce an improved land use and land cover map. Kantakumar and Neelamsetti [35] combined MLC, decision trees and unsupervised classification to develop a land use map and found that this combination improved the classification accuracy.

Most of the classification methods highlighted above have focused on the classification of land cover types associated with natural systems (e.g., forest, grassland and shrubland) or urban systems and tended to generalize cropland areas into a single or limited number of thematic classes [80]. Crop mapping in large agricultural land is often generated by supervised classification of multi-date satellite images acquired throughout the growing season [10, 11, 19, 43, 46, 49]. Combining classification methods with information about vegetation dynamics changes (vegetation phenology) derived from multi-temporal vegetation indexes (VI) is also powerful for crops mapping $[40,46,50,80]$ and for distinguishing the different land covers with a similar phenology trend [6].
In this study, we followed the lead of many researchers who have recognized the benefits of using multi-seasonal satellite images and information about vegetation phenology for land cover mapping. The developed approach aimed to generate a high accuracy land cover map for a large agricultural area. Landsat 8 images (resolution of $30 \mathrm{~m}$ ) were chosen as remote sensed data. The northeastern part of Tunisia was selected as a study case. This area was selected in our study due to the variety of land cover that it includes and the need for accurate and up-todate information on land cover distribution to address recent environmental issues and agriculture challenges there. The application of this approach to the whole of Tunisia is possible in the future to update the existing land cover maps generated in 2005 using SPOT and Landsat 5 satellite images of spring and summer 1999.

\section{Materials and methods}

\section{Study area}

This study focused on the north-eastern part of Tunisia (Fig. 1). This area is located on the satellite path 191 and rows 34 and 35 . It covers an area of approximately $29,000 \mathrm{~km}^{2}$ (17.7\% of the total area of Tunisia). The geography of the study area is characterized by fertile plains in the north and low steppe with some fertile plains in the south. The annual precipitation ranges between 400 and $600 \mathrm{~mm}$ and the climate is from humid in the north to semiarid in the south. These characteristics make the northern part the most cultivated area in Tunisia and the southern part an agro-pastoral region. The majority of agricultural fields in the study area are planted with cereals in November and harvested in the subsequent month of April. The other fields are exploited for vegetables, pasture, citrus, vineyard, olive and fruit cultivation.

\section{Satellite data pre-processing}

Satellite data consist of multi-spectral images of the Earth surface collected by satellites at different time periods and with different resolutions. A lot of satellites have been launched by the National Aeronautics and Space Administration (NASA) since 1972 to capture the daily global data about the Earth [74]. The most recent one is Landsat 8 which was launched in 2013. In our study, ortho-rectified and terrain corrected Level 1T Landsat 8 images were downloaded from the website of the United States Geological Survey (http://glovis.usgs. gov/). Data were processed by the Level 1 Product Generation System (LPGS) and provided in GeoTIFF format with UTM projection and WGS84 datum [76]. 
Fig. 1 Location of the study area. The source information of the land cover map is available on the website of the Global Land Cover Network (GLCN) with a resolution of $300 \mathrm{~m}$. http://www.glcn.org/databases/ lc_gc-africa_en.jsp [22]

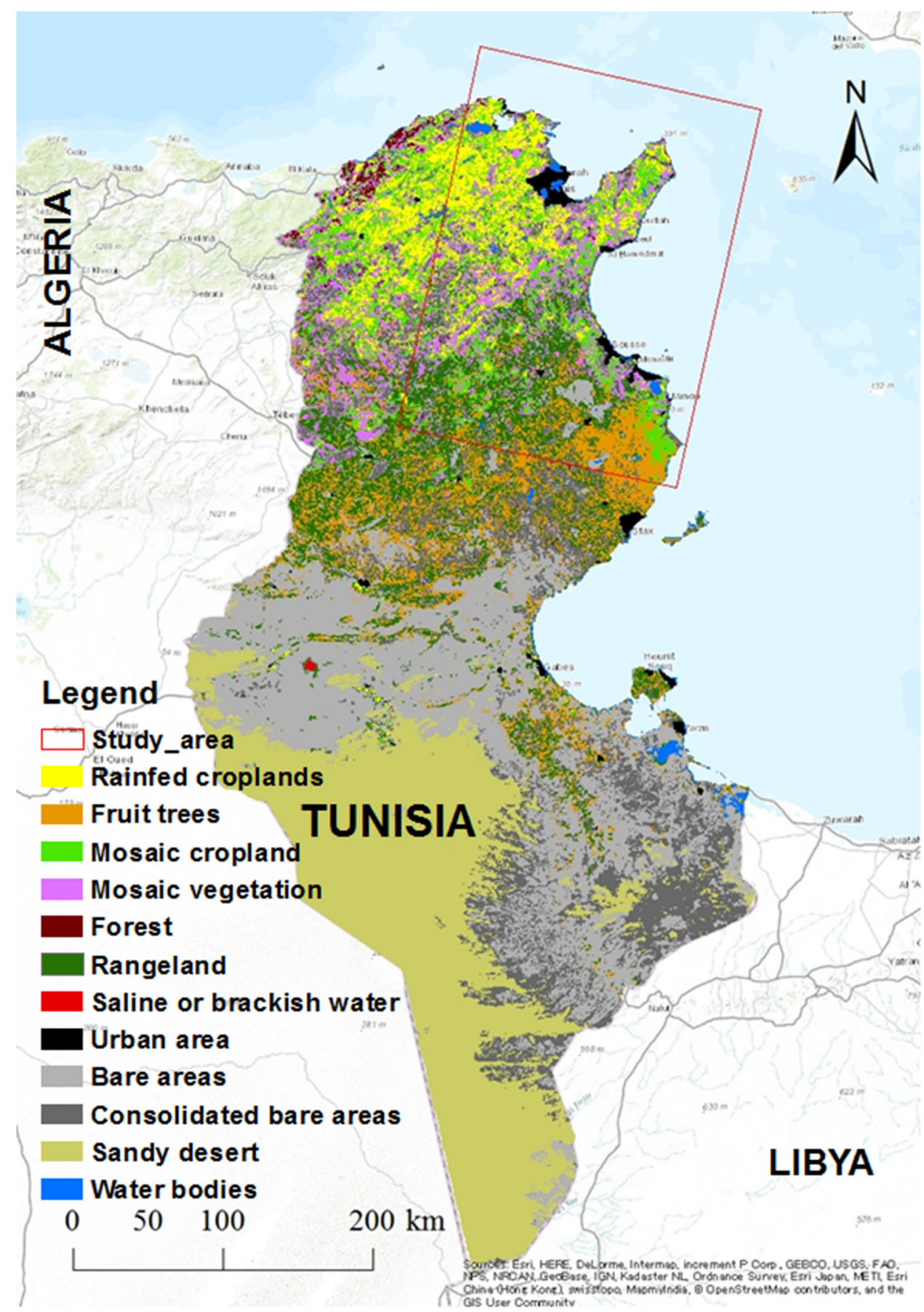

Systematic radiometric and geometric corrections have already been applied to this product by incorporating ground control points and employing a digital elevation model (DEM) for topographic correction [62]. Downloaded datasets were pre-processed in accordance with the Eq. 1. This equation was given in the USGS website and aimed to convert raw digital number (DN) to top of atmosphere (TOA) reflectance with correction for sun angle $[5,75,84]$.
$\rho_{\lambda}=\frac{M_{p} Q_{\mathrm{cal}}+A_{p}}{\sin \left(\theta_{\mathrm{SE}}\right)}$

where: $\rho_{\lambda}=$ TOA reflectance for band $\lambda . M_{p}=$ Band specific multiplicative rescaling factor. $Q_{\text {cal }}=$ Quantized and calibrated standard product pixel values (DN). $A_{p}=$ Band specific additive rescaling factor. $\theta_{\mathrm{SE}}=$ Local sun elevation angle in radians. $M_{p}, A_{p}$ and $\theta_{\mathrm{SE}}$ are given in the metadata file provided in the Level $1 \mathrm{~T}$ data. 


\section{Monitoring vegetation phenology}

Time series of the enhanced vegetation index (EVI) and/or the normalized difference vegetation index (NDVI) have often been used to identify vegetation phenological profiles [24, 34, 64, 68, 78, 79]. The NDVI, derived from greenness sensitive bands of satellite images, offers an important means for evaluating efficiently and objectively the phenological characteristics over large areas $[20,21,28,36,58]$. In our study, the phenology of different types of land cover was monitored from NDVI time series. First, multi-temporal Landsat 8 images for the growing season 2013/2014 were downloaded and pre-processed. Then, The NDVI was calculated for each image according to the following equation: $\mathrm{NDVI}=(\mathrm{NIR}-\mathrm{Red}) /$ (NIR + Red) where NIR and Red are the near infra-red and red bands, respectively. For each land cover type, three different fields were identified from field investigations and Google Earth Imagery. We tried to select fields which are as far as possible from transition zones and as close as possible to pure land cover class. Then, the NDVI of each land cover at a specific date was determined as the average NDVI of the three fields from the generated NDVI image acquired at the same date. Finally, the temporal NDVI profile of each land cover was monitored.

\section{Image classification approaches}

Three classification approaches were applied to develop the land cover map of our study area: conventional supervised classification using single date images, conventional supervised classification using multi-date images and a new approach based on vegetation phenology.

\section{Conventional supervised classification using single date images}

In this approach, Landsat 8 satellite images were classified by means of the MLC, which is a widely used algorithm in the supervised classification method [1, 3, 4, 17, 25, 38, 42]. This classifier was selected since it takes into account the variance-covariance within the class distributions and for normally distributed data $[16,54]$. The supervised classification was performed using a single date multiband image acquired in different seasons (spring, summer, winter). Properties of these images are given in Table 1.

The Landsat 8 dataset has nine spectral bands. In our study, only bands 2, 3, 4, 5, 6 and 7 were used. Band 2 was chosen for its high albedo in urban areas. Bands 3, 4 and 5 were chosen for their rich vegetation information. Bands 6 and 7 were chosen thanks to their ability to discriminate between water or wet lands and dry lands. To facilitate data handling and classification processing, these bands were
Table 1 Properties of satellite data for land cover classification

\begin{tabular}{lll}
\hline Path/row & Date & Season \\
\hline 191/34 and 191/35 & April 09, 2014 & Spring \\
$191 / 34$ and 191/35 & June 28, 2014 & Summer \\
$191 / 34$ and 191/35 & January 06, 2015 & Winter \\
\hline
\end{tabular}

combined in one multiband raster dataset by means of the "Composite Bands" tool including in ArcGIS 10.2.2 Arc toolbox.

Training samples were selected from data of two field surveys performed in March 2015 and January 2016. Camera photos with geographic coordinates were captured using GPS camera (GARMIN Oregon ${ }^{\circledR}$ 650). Then, the land cover type was decided. Because of the difficulty to access to some regions, additional training samples were selected from Google Earth Imagery. Figure 2 shows the spatial distribution of the collected training samples. A total of 1090 samples belonging to 13 classes were collected for the training stage (Table 2).

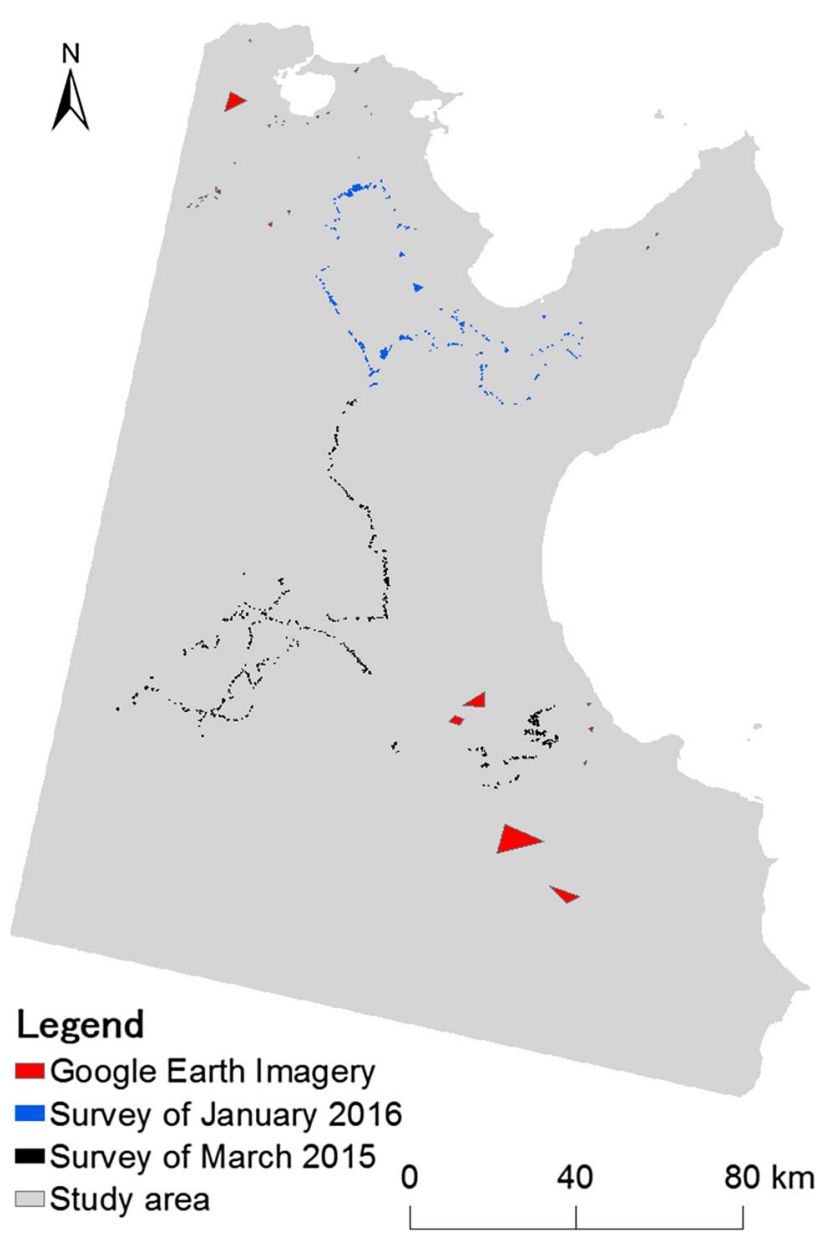

Fig. 2 Spatial distribution of collected training samples 
Table 2 Training data used in the classification approaches

\begin{tabular}{|c|c|c|c|c|c|}
\hline \multirow[t]{2}{*}{ Class } & \multicolumn{5}{|l|}{ Training data } \\
\hline & $\begin{array}{l}\text { Survey } \\
\text { of March } 2015\end{array}$ & $\begin{array}{l}\text { Survey } \\
\text { of January } 2016\end{array}$ & $\begin{array}{l}\text { Google Earth } \\
\text { Imagery }\end{array}$ & Total & $\begin{array}{l}\text { Total number } \\
\text { of pixels }\end{array}$ \\
\hline Pasture & 87 & 20 & 6 & 113 & 1555 \\
\hline Fruit trees & 16 & 28 & 0 & 44 & 660 \\
\hline Cereals & 191 & 115 & 0 & 306 & 18,472 \\
\hline Forest & 55 & 13 & 10 & 78 & 5631 \\
\hline Olive trees & 318 & 64 & 0 & 382 & 18,432 \\
\hline Citrus & 5 & 27 & 0 & 32 & 466 \\
\hline Rocky lands & 5 & 1 & 1 & 7 & 64 \\
\hline Sabkha & 1 & 0 & 3 & 4 & 66,254 \\
\hline Shrublands & 37 & 1 & 0 & 38 & 626 \\
\hline Urban & 6 & 6 & 8 & 20 & 3524 \\
\hline Vegetables & 7 & 25 & 0 & 32 & 911 \\
\hline Vineyard & 0 & 24 & 5 & 29 & 286 \\
\hline Water & 0 & 0 & 5 & 5 & 14,337 \\
\hline
\end{tabular}

The scatter plots of the training samples in the different bands used for the classification were determined to evaluate their distribution. If the training samples represent the different classes accurately, their scatter plots should not overlap.

\section{Conventional supervised classification using multi-date images}

This approach is similar to the above mentioned one. However, in this approach, the supervised classification was performed using the information of the three multiband images at once (Table 1). The purpose of this approach was to consider the seasonal change of vegetation in the classification process.

\section{New approach for land cover mapping}

The classification approach proposed in this work is based on vegetation phenology. It consists of two steps: (1) dividing the study area according to the seasonal change of NDVI in cereals fields. (2) Applying supervised classification using the information of the three multiband images. The workflow chart of the proposed approach is shown in Fig. 3.

Dividing the study area This step was aimed to divide the study area into three different land use groups: inland water, low change and high change. Inland water is represented by water (reservoirs and lakes) and sabkha areas. The low change group included non-vegetated lands (urban area and rocky land), natural vegetation (forest and

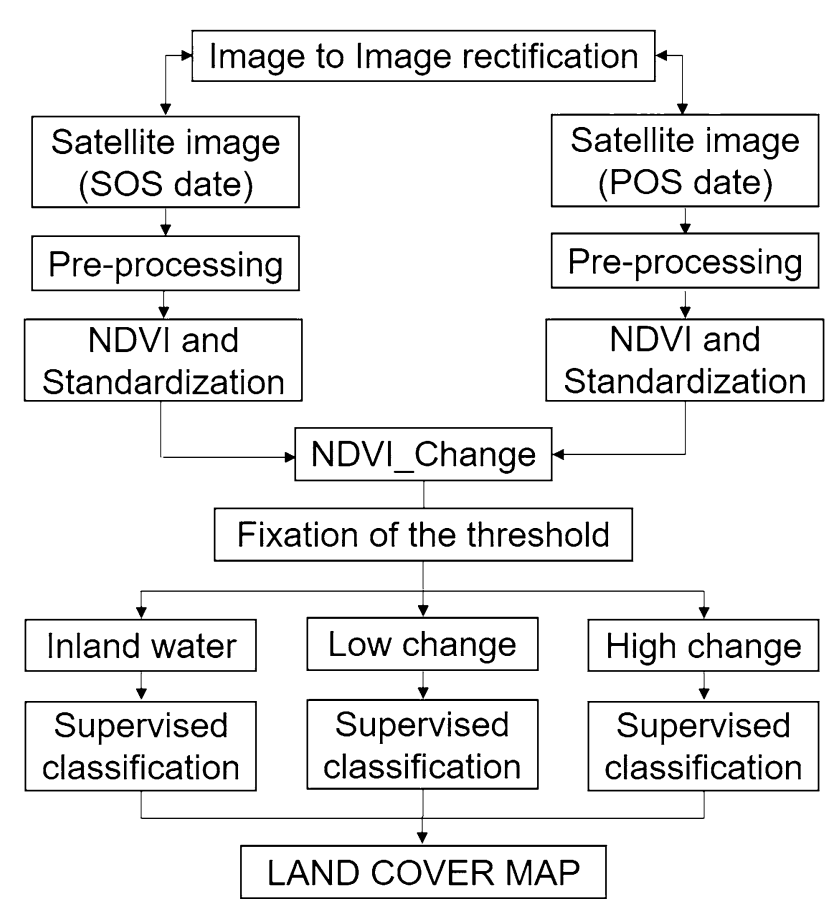

Fig. 3 Workflow chart of the proposed approach

shrublands) and trees (fruit trees, citrus, vineyard and olive). The high change group included seasonal crops such as cereals, pasture and vegetables which have a similar phenology. To divide the study area, we went through a three step procedure:

- Analysis of cereals phenology and determination of Start of Season (SOS) and Peak of Season (POS) date: SOS and POS have usually been established as indicators of phenology change [24, 77]. Several 
researchers have determined these indicators from vegetation index time series [31, 64, 65, 83]. Different measures of SOS can be derived from the time series of NDVI [6]: the time at which NDVI values started to increase beyond a certain threshold [44, 81]; inflection points [65] or the time at which the NDVI starts to increase [51]. The POS is usually determined as the maximum value of the vegetation index [65]. In our study, we assumed that cereals, pasture and vegetables have the same phenology trend. Then, we analyzed the phenology of cereals as it represents the major land cover in the study area to determine the date of SOS and POS. The SOS was identified as the time at which the NDVI starts to increase and the POS was identified as the date of the maximum value of NDVI during the spring (March-April).

- Standardization of NDVI:

Landsat 8 satellite images acquired about the SOS and POS dates were downloaded and pre-processed (Table 3). Then, the NDVI was calculated for each image. Finally, the NDVI was standardized from 0 to 1 by taking into consideration the global maximum and global minimum values. The standardization process aimed to equalize the attributes of each image and minimize the noise caused by difference in radiometry..

- Calculation of NDVI_Change:

A new index termed NDVI_Change (NDVI_C) was developed. It was calculated according to the following equation (Eq. 2):

NDVI_Change $=1-\frac{\text { Standarized NDVI }(\text { SOS date })}{\text { Standarized NDVI (POS date })}$

Its numerical value gives a quantified assessment of the degree of seasonal change of crops between the POS and SOS and it ranged between -1 and 1 . To facilitate the analysis of NDVI_C image, a sample (a field of about $92 \mathrm{~km}^{2}$ ) covered mainly with cereals and forest was selected. Then, the histogram distribution of NDVI-C value was determined by means of the fundamental package for scientific computing with Python (NumPy). Typically, the histogram presented two peaks that refer to cereals and forest in the small scale (the sample) or high change and low change groups in the large scale (study area). To fix a

Table 3 Properties of satellite data used for dividing the study area

\begin{tabular}{lll}
\hline Path/row & Date & Season \\
\hline 191/34 and 191/35 & April 09, 2014 & POS \\
191/34 and 191/35 & November 19, 2014 & SOS \\
\hline
\end{tabular}

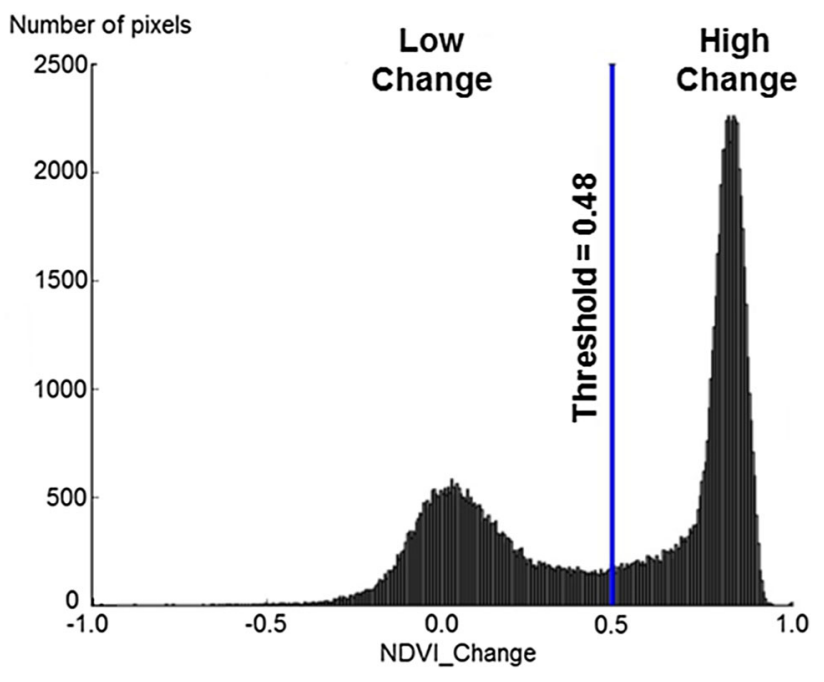

Fig. 4 Example of NDVI-C distribution (clip of $91.8 \mathrm{~km}^{2}$; date of SOS image: 19/11/2014 and date of POS image: 09/04/2014)

threshold between these two groups, a third polynomial plot was determined for the data comprised between the two peaks, then the threshold was decided at the point where the derivative $(\mathrm{d} y / \mathrm{d} x)$ was equal to 0 . High change group had an NDVI-C higher than the threshold. Meanwhile, a low change group had an NDVI_C less than the threshold (Fig. 4). This method also allowed us to distinguish inland waters which had a zero NDVI value whatever the season. Therefore, it had no numerical NDVI-C value.

Supervised classification The supervised classification applied in this approach is also based on the MLC. The information of three multiband images was considered (same as the conventional supervised classification approach using multi-date images). However, the classification was applied for each group separately after dividing the study area. Fields used for irrigated vegetables can have a low NDVI_C, and thus be included in the low change group. To avoid classification errors, training samples corresponding to vegetables were also involved in the classification stage of the low change group. The involved training samples for each group are shown in Table 4.

\section{Accuracy evaluation}

To assess the efficiency of different classification approaches, it is recommended to check the accuracy of the derived thematic maps. Accuracy assessment means the comparison of predicted results (classification results) to reference data that are assumed to be true [41, 59]. Generally, accuracy assessment is done by comparing randomly selected pixels to ground reference data 
Table 4 Training samples involved in the classification stage

Land cover Training samples

group

Inland water Water and sabkha

High change Cereals, vegetables and pasture

Low change Urban, forest, fruit trees, olive, citrus, vineyard, shrublands, rocky land, vegetables

$[2,52,57,70,85,86]$. Then, performing the error matrices and calculating the Kappa statistic [12]. Error matrices are cross tabulations of the selected pixels versus the ground reference data. The Kappa statistic incorporates the off diagonal elements of the error matrices (classification errors) and represents agreement obtained after removing the proportion of agreement that could be expected to occur by chance [85]. The random selection method can decrease or eliminate the possibility of bias [12]. For each land cover type, 50 pixels were generated using the stratified random sampling method and then checked using Google Earth Imagery. Figure 5 shows an example of the random

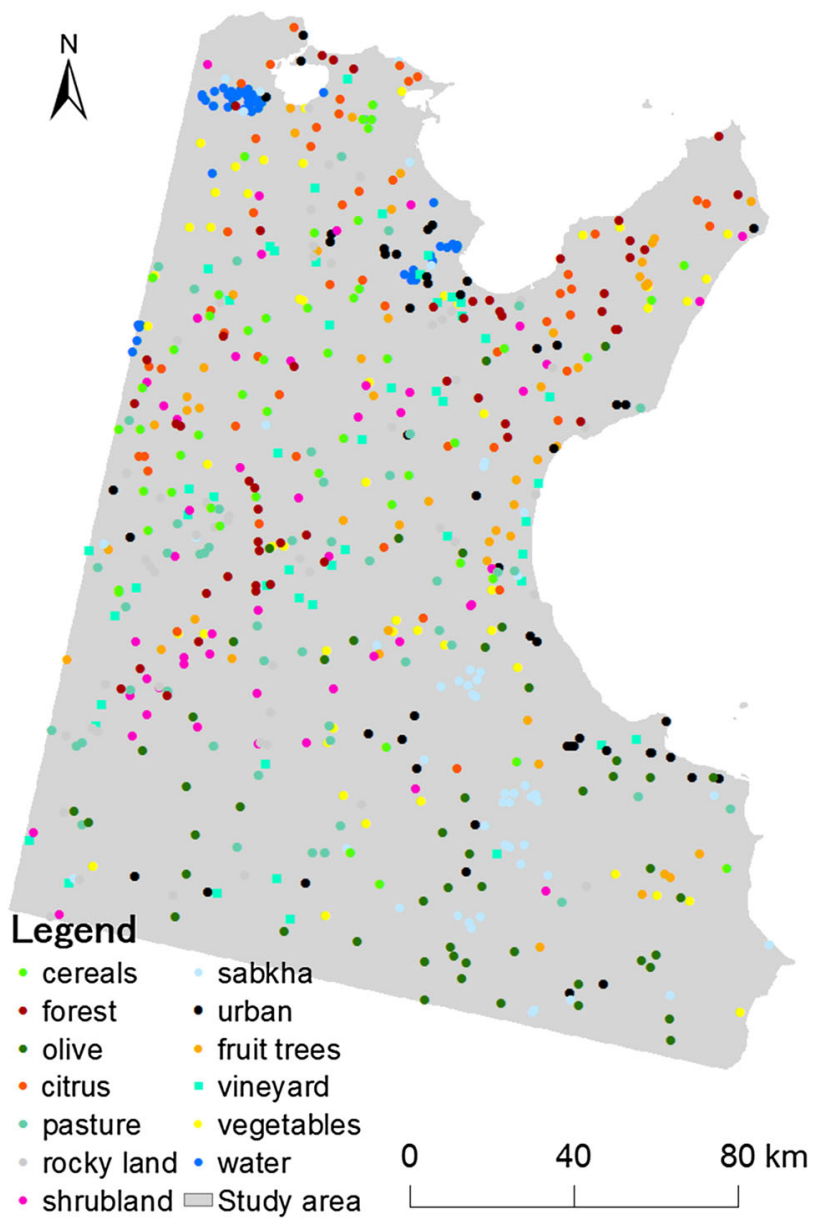

Fig. 5 Example of random distribution of validation samples distribution of validation samples. The error matrix was prepared for classes from each classified image and then the Kappa coefficient was computed.

\section{Results}

\section{Vegetation phenology monitoring}

NDVI time series for 1 year (from August 2013 to July 2014) were processed to identify the phenology trend of different land cover. Eleven land cover types were involved in this assessment. Water and sabkha land cover types were not considered because they are not covered by vegetation and so they have an NDVI equal to 0 whatever the season. The phenology profiles are shown in Fig. 6 .

Two groups of land cover could be distinguished depending on time series variation of the NDVI: low change group and high change group. Low change group was characterized by a low seasonal variation of the NDVI and included forest, olive, shrubland, fruit trees, citrus, vineyard, rocky land and urban areas (Fig. 6a). Except vineyard, these land covers had a constant NDVI throughout the year with a slight variation due to the solar zenith variations which affects the reflectance of vegetation [30]. Regarding the phenology of citrus, olive, shrublands and fruit trees, an increase in the NDVI was observed from around February 15. This increase can be explained by the

(a)

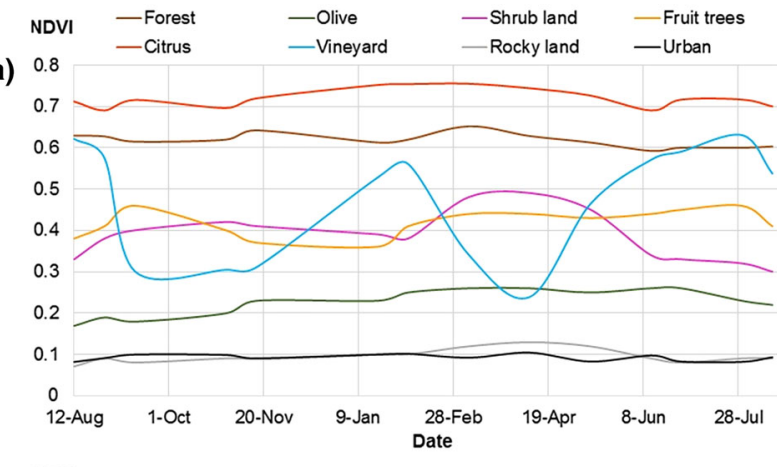

(b)

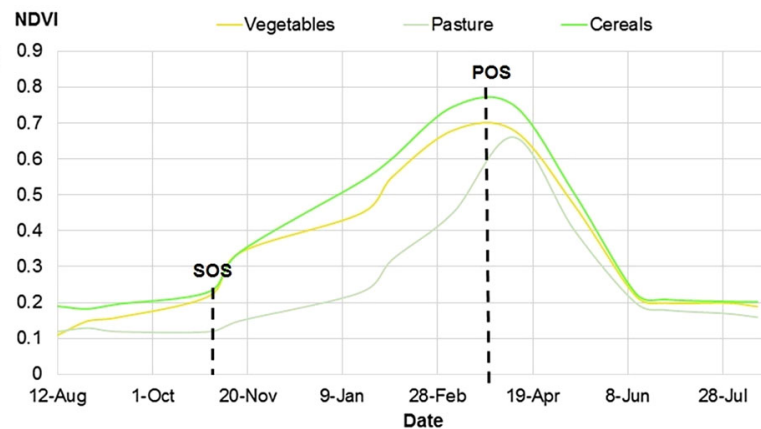

Fig. 6 Vegetation phenology monitoring for low change group (a) and high change group (b) 
start of the plant flowering and growing season and the growing of grass between the trees. Forest lands found in the study area are evergreen. Thus, they had a constant NDVI throughout the year. Urban areas and rocky lands also had low and constant NDVI throughout the year. Generally, the vineyard starts growing from the end of March and reaches the maximum of growing in the summer (mid-July). In Fig. 6a, we noticed two sudden drops of vineyard NDVI. The first one was around early September and the second around the end of January. These two drops can be explained by specific cultivation methods such as the technique of high pergola, covering the field by plastic cover and branch cuttings.

High change group was characterized by high seasonal change and included cereals, vegetables and pasture (Fig. 6b). The phenology of these three land covers was found to be similar and had three growing stages: seeding stage or SOS, maximum growing stage or POS and harvesting stage. The analysis of cereals phenology shows that the SOS started from early November while the POS was reached around early April. In general, the SOS depends at the start of rainy season [33]. In the proposed approach, we used the images acquired on April 09, 2014 and November 19, 2014 as POS and SOS images because of the limited number of cloud-free images in the Landsat 8 database.

\section{Land cover classification}

\section{Spatial extent of land cover classes}

We used three approaches for mapping the land cover. Each approach gave a different thematic land cover map (Fig. 7). The land cover area derived from the different approaches showed differences in spatial extent (Table 5). However, all the approaches were able to present olive and cereals as major land cover in the study area. Using single date images, land cover area statistics showed small differences in spatial extent whatever the used image except for citrus, cereals and vegetables. Stacking the information of the three satellite images into the supervised classification approach gave a new spatial statistics of the different land covers compared to the single date approach (differences $\leq 6 \%$ ). Some pixels classified as fruit trees in the single date approach were now classified as cereals in the multi-date approach (Fig. 7a-d). Compared with the multidate approach, the proposed approach gave low differences in the spatial extent of land cover (within $2 \%$ ) except for pasture. It was observed that about $50 \%$ of lands classified as pasture in the multi-date approach were classified as, especially olive in the proposed approach (Fig. 7d, e). This is due to dividing the study area based on the NDVI_C threshold before the application of the supervised classification (Fig. 8). Using this threshold, only pixels that had high seasonal change between spring and autumn were included in the high change group, and can thus be classified as pasture, vegetables or cereals.

\section{Accuracy assessment of the thematic maps}

To assess the accuracy of each generated thematic land cover map, five error matrices were prepared (Tables 6, 7, $8,9,10)$. In the case of a single date images approach, the overall accuracy did not exceed $55 \%$ whatever the season of the used image (spring, summer or winter). However, the classification accuracy of pasture, cereals and vegetables showed the best results in the case of spring images but it did not exceed 72, 78 and $42 \%$, respectively (Table 6). The highest user's accuracies in the single date images approach were found for forest, urban, sabkha and water classes which have a relatively constant reflectance whatever the season. Table 9 shows that stacking the information of the three satellite images in the supervised classification improved the classification accuracy of pasture, cereals and vegetables up to 86,80 and $76 \%$, respectively. The classification accuracy of other land cover classes was $96 \%$ for forest, $80 \%$ for citrus, $88 \%$ for shrublands and $72 \%$ for vineyard. However, it was still low for rocky lands and fruit trees classes. It was found that about $20 \%$ of the fruit trees pixels were classified as shrublands. Classification accuracy of the different land cover classes generated by the proposed approach is given in Table 10. The user's accuracy of most classes exceeded $90 \%$ (cereals, forest, olive, citrus, sabkha, shrublands, urban and water). As compared with the conventional supervised approach using multi-date images (Table 9), the classification accuracy of all land cover categories was improved. This proves that it is important to divide the study area before applying the classification process. The classification accuracy of rocky lands was also improved but it was still low (50\%). The difference between the user's and producer's accuracies which represents the percentage of wrong classification was found high in the single date approach. This percentage decreased significantly after the use of multi-date images or applying the proposed approach (Tables 6, 7, 8, 9, 10). The overall accuracy of the proposed approach (86\%) was found to outperform the conventional supervised approach using multi-date images $(76 \%)$ and single date images (54-55\%). Kappa coefficient gives an idea about the degree of clarity of the generated map. The Kappa for the proposed approach was equal to 0.85 (Table 10) which means $85 \%$ of error reduction. Reducing the number of classes by dividing the study area improved the clarity of the generated land cover map by reducing most of the errors during the classification process. 
Fig. 7 Land cover maps generated from the conventional supervised classification using single date images $(\mathbf{a}-\mathbf{c})$, multidate images (d) and the proposed approach (e) (a) Spring image

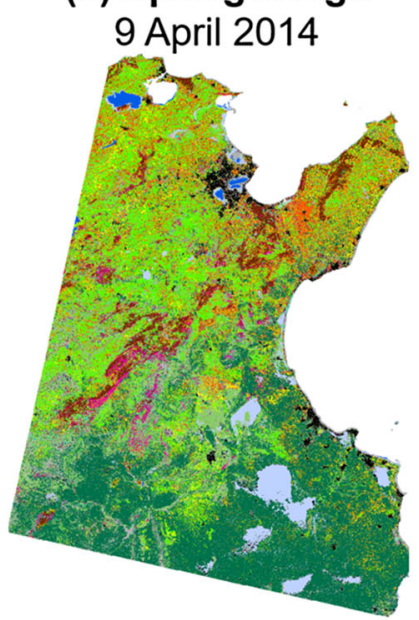

(d) Multi-date image

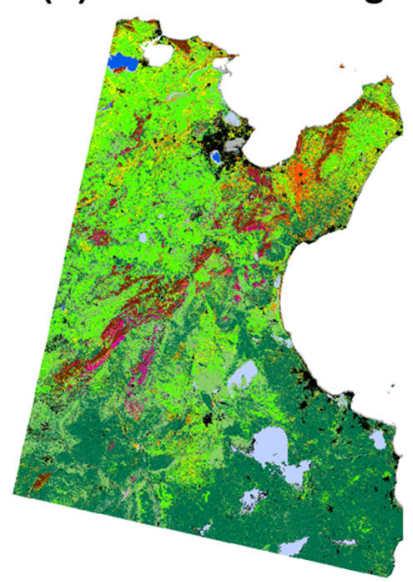

(b) Summer image

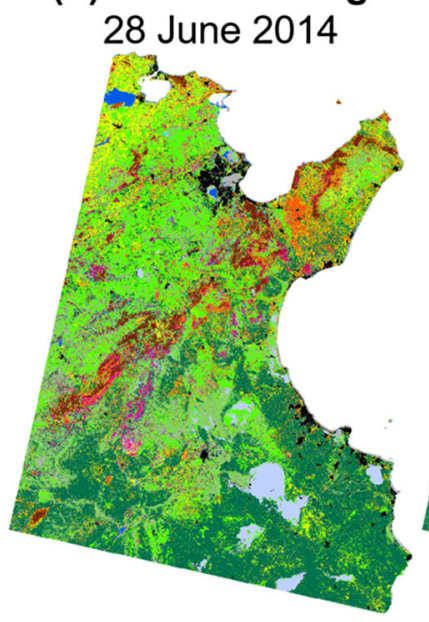

(e) Proposed approach

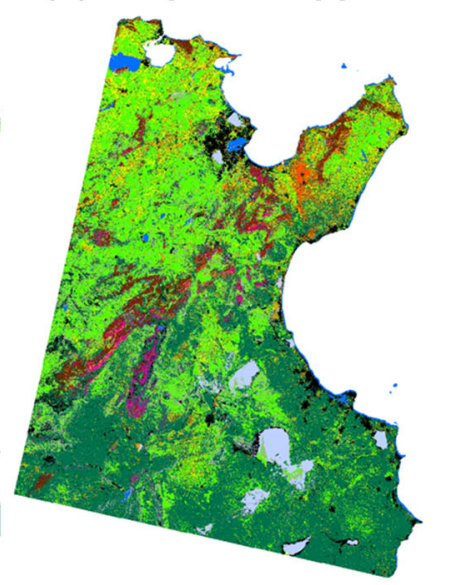

(c) Winter image 06 January 2015

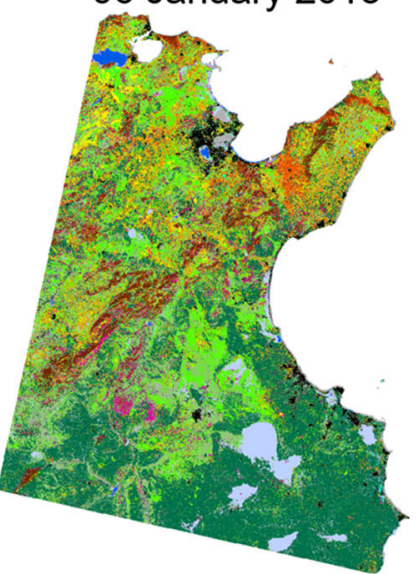

Legend

$\square$ Pasture

Fruit trees

Cereals

- Forest

Olive

Citrus

$\square$ Rocky lands

$\square$ Sabkha

Shrub lands

urban

$\square$ Vegetables

$\square$ Vineyard

Water

$0 \quad 40 \quad 80 \mathrm{~km}$

\section{Discussion}

Several researchers have investigated the usefulness of considering vegetation phenology for land cover mapping either through the use of multi-seasonal satellite images in the classification approaches $[7,53,55,56]$ or vegetation index $[26,40,46,50,80]$. Our results further substantiate the utility of dividing a cropland dominated area based on cereals phenology before applying a supervised classification.

At our preliminary study using single date satellite images, we confirm the incapability of only one satellite image to map land cover in an agricultural land with a fairly heterogeneous land use. That approach was not able to discriminate between crops that have a similar phenology trend, whatever the date of image acquisition. Referring to Table 5, cereals, vegetables and citrus have high differences in spatial extent when we used a single date approach. This may be due to the similarity of reflectance of some vegetation such as forest and citrus, and cereals and vegetables at a specific season. The overall accuracy of the classification approach using single date image did not exceed $55 \%$. In contrast, Saadat et al. [63] found that a single Enhanced Thematic Mapper Plus image acquired in late summer gave a classification accuracy of $95 \%$. However, in their research, they generalized cropland areas into a limited number of thematic classes based on vegetation density and incorporated climatic and topographic conditions in the classification approach.

Involving multi-seasonal satellite images in the classification approach gave a new spatial extent and helped to avoid the classification errors caused by the high level of spectral confusion in single date images [32]. This was reflected in our work by the improvement of classification accuracy to $78 \%$ in the case of multi-date approach. In the same context, Roumenina et al. [61] used multi-temporal PROBA-V data for identifying different crops and found that combining three to four images acquired in different seasons improved the classification accuracy up to 74 and $77 \%$, respectively. The used satellite images acquired in different crops growing stages incorporated the information of crops phenology in the classification approach and 
Table 5 Results of different approaches for the spatial extent of land cover classes

\begin{tabular}{|c|c|c|c|c|c|}
\hline \multirow[t]{2}{*}{ Land cover class } & \multicolumn{3}{|c|}{ Single date image } & \multirow[t]{2}{*}{ Multi-date images } & \multirow[t]{2}{*}{ Proposed approach } \\
\hline & April 09, 2014 & June 28, 2014 & January 06, 2015 & & \\
\hline Pasture & 15.94 & 16.68 & 15.75 & 18.17 & 9.68 \\
\hline Fruit trees & 8.10 & 7.57 & 8.99 & 5.85 & 5.66 \\
\hline Cereals & 16.14 & 17.39 & 12.94 & 18.12 & 20.43 \\
\hline Forest & 4.21 & 3.80 & 4.71 & 3.79 & 3.73 \\
\hline Olive & 29.86 & 31.40 & 32.91 & 37.14 & 41.35 \\
\hline Citrus & 5.52 & 1.19 & 1.81 & 0.81 & 0.89 \\
\hline Rocky lands & 4.43 & 3.06 & 3.13 & 1.62 & 1.28 \\
\hline Sabkha & 4.18 & 3.53 & 5.12 & 3.32 & 3.11 \\
\hline Shrublands & 3.40 & 3.55 & 5.00 & 1.48 & 1.75 \\
\hline Urban & 2.91 & 3.39 & 3.40 & 4.85 & 6.17 \\
\hline Vegetables & 4.15 & 7.02 & 5.17 & 4.42 & 5.20 \\
\hline Vineyard & 0.65 & 0.94 & 0.64 & 0.09 & 0.11 \\
\hline Water & 0.49 & 0.49 & 0.44 & 0.33 & 0.63 \\
\hline Total & 100.0 & 100.0 & 100.0 & 100.0 & 100.0 \\
\hline
\end{tabular}

All values are expressed in percent $(\%)$

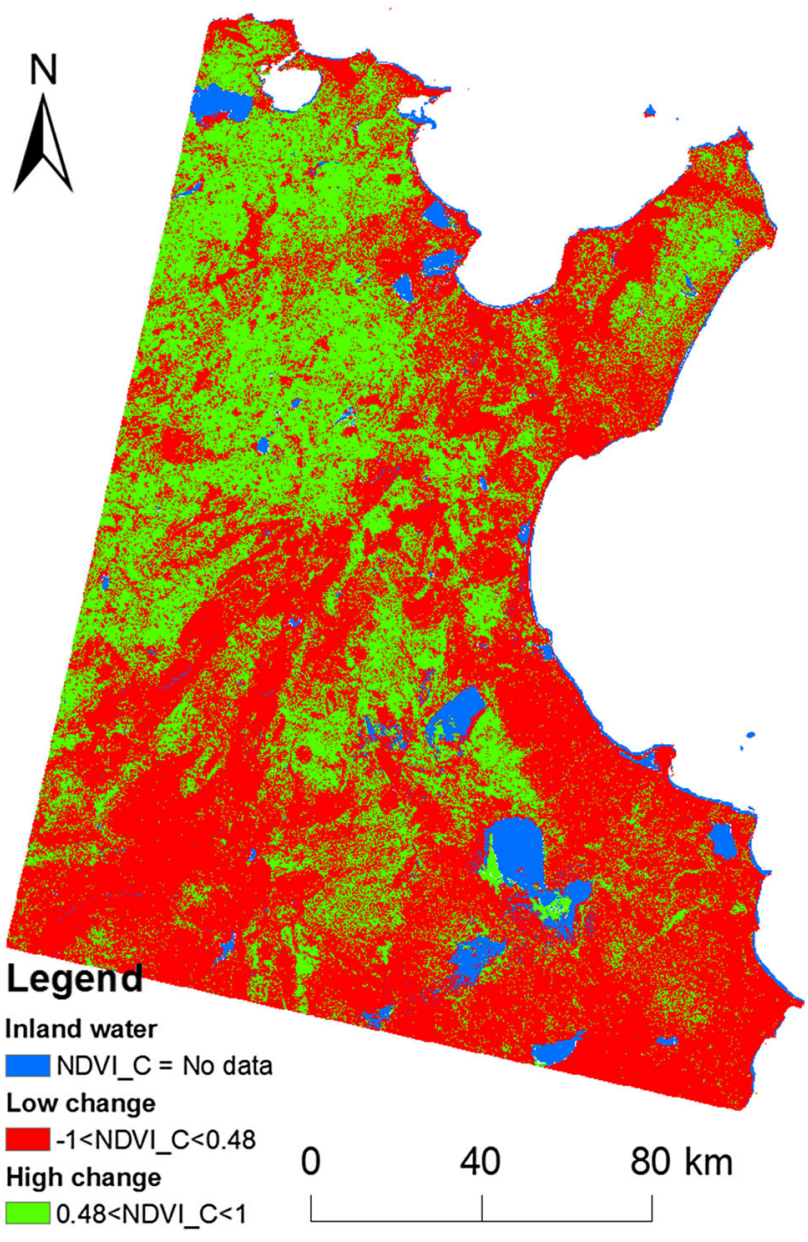

Fig. 8 The generated NDVI_Change image enhanced the ability of the classifier to differentiate between crops. The benefits of using multi-date images on the classification accuracy were well confirmed in our results and previously reported in other studies [15, 55, 67].

The proposed approach was found able to discriminate between heterogeneous land cover classes including those which have similar spectral reflectance with high accuracy (overall accuracy $=86 \%$ ). The classification accuracy of rocky land class was improved comparing with the conventional approaches. However, it was still low (50\%). This could be explained by two reasons: the limited number of training samples involved in the supervised classification and the small area of rocky lands in the study area on the one hand, and the high degree of resemblance between the reflectance of rocky lands and urban area or coastal soils on the other hand. In our approach, dividing the study area into three groups of land use improved the classification accuracy. This preliminary step helped to decrease the misclassification errors and spectral confusion problem. A similar investigation was proposed by Lo and Choi [45] who applied an unsupervised ISODATA clustering to identify natural homogenous subclasses depending on spectral similarity before applying a supervised method for each subclass. They found that this hybrid approach improved the classification accuracy up to $91.5 \%$ comparing with the conventional ISODATA clustering methods (overall accuracy $=90.25 \%$ ), the supervised fuzzy (overall accuracy $=77.75 \%$ ) and the MLC (overall accuracy $=76.75 \%)$. In that approach, the number of clusters 
Table 6 Error matrix of supervised classification using spring image

\begin{tabular}{|c|c|c|c|c|c|c|c|c|c|c|c|c|c|c|c|c|}
\hline & \multirow[t]{2}{*}{ Class ID } & \multicolumn{15}{|c|}{ Reference data } \\
\hline & & 1 & 2 & 3 & 4 & 5 & 6 & 7 & 8 & 9 & 10 & 11 & 12 & 13 & Total & U. Acc (\%) \\
\hline \multirow[t]{15}{*}{ Classified data } & 1 & 36 & 1 & 3 & 1 & 5 & 0 & 0 & 0 & 1 & 2 & 1 & 0 & 0 & 50 & 72 \\
\hline & 2 & 11 & 9 & 8 & 2 & 4 & 0 & 0 & 1 & 10 & 1 & 4 & 0 & 0 & 50 & 18 \\
\hline & 3 & 5 & 1 & 39 & 0 & 4 & 0 & 0 & 0 & 1 & 0 & 0 & 0 & 0 & 50 & 78 \\
\hline & 4 & 0 & 0 & 0 & 47 & 0 & 0 & 0 & 0 & 2 & 0 & 1 & 0 & 0 & 50 & 94 \\
\hline & 5 & 8 & 0 & 1 & 0 & 39 & 0 & 0 & 0 & 2 & 0 & 0 & 0 & 0 & 50 & 78 \\
\hline & 6 & 10 & 0 & 21 & 0 & 2 & 7 & 0 & 0 & 2 & 0 & 8 & 0 & 0 & 50 & 14 \\
\hline & 7 & 10 & 0 & 3 & 5 & 1 & 0 & 0 & 0 & 23 & 0 & 5 & 3 & 0 & 50 & 0 \\
\hline & 8 & 1 & 0 & 0 & 2 & 1 & 0 & 0 & 40 & 0 & 0 & 2 & 0 & 4 & 50 & 80 \\
\hline & 9 & 5 & 4 & 0 & 3 & 4 & 1 & 0 & 0 & 29 & 0 & 4 & 0 & 0 & 50 & 58 \\
\hline & 10 & 2 & 0 & 0 & 1 & 2 & 0 & 1 & 2 & 0 & 42 & 0 & 0 & 0 & 50 & 84 \\
\hline & 11 & 10 & 1 & 8 & 0 & 8 & 0 & 0 & 0 & 2 & 0 & 21 & 0 & 0 & 50 & 42 \\
\hline & 12 & 10 & 3 & 1 & 6 & 0 & 0 & 0 & 1 & 20 & 0 & 4 & 5 & 0 & 50 & 10 \\
\hline & 13 & 0 & 0 & 0 & 0 & 0 & 0 & 0 & 6 & 0 & 0 & 0 & 0 & 44 & 50 & 88 \\
\hline & Total & 108 & 19 & 84 & 67 & 70 & 8 & 1 & 50 & 92 & 45 & 50 & 8 & 48 & 650 & \\
\hline & P. Acc $(\%)$ & 33 & 47 & 46 & 70 & 56 & 88 & 0 & 80 & 32 & 93 & 42 & 63 & 92 & & \\
\hline
\end{tabular}

Overall classification accuracy $=0.55$; Kappa coefficient $=0.51$

$P$. Acc producer's accuracy, $U$. Acc user's accuracy, 1 pasture, 2 fruit trees, 3 cereals, 4 forest, 5 olive, 6 citrus, 7 rocky lands, 8 sabkha, 9 shrublands, 10 urban, 11 vegetables, 12 vineyard, 13 water

Table 7 Error matrix of supervised classification using summer image

\begin{tabular}{|c|c|c|c|c|c|c|c|c|c|c|c|c|c|c|c|c|}
\hline & \multirow[t]{2}{*}{ Class ID } & \multicolumn{15}{|c|}{ Reference data } \\
\hline & & 1 & 2 & 3 & 4 & 5 & 6 & 7 & 8 & 9 & 10 & 11 & 12 & 13 & Total & U. Acc $(\%)$ \\
\hline \multirow[t]{15}{*}{ Classified data } & 1 & 31 & 0 & 1 & 0 & 9 & 0 & 0 & 2 & 3 & 1 & 3 & 0 & 0 & 50 & 62 \\
\hline & 2 & 15 & 10 & 2 & 0 & 8 & 1 & 0 & 0 & 7 & 0 & 7 & 0 & 0 & 50 & 20 \\
\hline & 3 & 8 & 0 & 31 & 0 & 3 & 0 & 1 & 0 & 0 & 0 & 7 & 0 & 0 & 50 & 62 \\
\hline & 4 & 0 & 1 & 0 & 45 & 0 & 1 & 0 & 0 & 3 & 0 & 0 & 0 & 0 & 50 & 90 \\
\hline & 5 & 6 & 2 & 2 & 0 & 31 & 0 & 0 & 0 & 6 & 2 & 1 & 0 & 0 & 50 & 62 \\
\hline & 6 & 3 & 7 & 0 & 7 & 0 & 17 & 0 & 0 & 10 & 0 & 6 & 0 & 0 & 50 & 34 \\
\hline & 7 & 17 & 1 & 1 & 0 & 2 & 0 & 7 & 1 & 0 & 1 & 1 & 0 & 19 & 50 & 14 \\
\hline & 8 & 8 & 0 & 0 & 0 & 0 & 0 & 0 & 38 & 3 & 0 & 0 & 0 & 1 & 50 & 76 \\
\hline & 9 & 3 & 4 & 0 & 0 & 2 & 0 & 0 & 0 & 37 & 0 & 4 & 0 & 0 & 50 & 74 \\
\hline & 10 & 1 & 0 & 0 & 0 & 0 & 0 & 3 & 4 & 6 & 36 & 0 & 0 & 0 & 50 & 72 \\
\hline & 11 & 12 & 2 & 3 & 3 & 8 & 1 & 0 & 0 & 5 & 0 & 16 & 0 & 0 & 50 & 32 \\
\hline & 12 & 11 & 3 & 0 & 9 & 1 & 1 & 0 & 1 & 13 & 3 & 4 & 4 & 0 & 50 & 8 \\
\hline & 13 & 0 & 0 & 0 & 0 & 0 & 0 & 0 & 0 & 0 & 0 & 0 & 0 & 50 & 50 & 100 \\
\hline & Total & 115 & 30 & 40 & 64 & 64 & 21 & 11 & 46 & 93 & 43 & 49 & 4 & 70 & 650 & \\
\hline & P. Acc (\%) & 27 & 33 & 78 & 70 & 48 & 81 & 64 & 83 & 40 & 84 & 33 & 100 & 71 & & \\
\hline
\end{tabular}

Overall classification accuracy $=0.54$; Kappa coefficient $=0.505$

$P$. Acc producer's accuracy, U. Acc user's accuracy, 1 pasture, 2 fruit trees, 3 cereals, 4 forest, 5 olive, 6 citrus, 7 rocky lands, 8 sabkha, 9 shrublands, 10 urban, 11 vegetables, 12 vineyard, 13 water

needs to be large enough to preserve the homogeneity of each class for the labeling process. Otherwise, some clusters can include mixed pixels [45].
Comparing with other approaches that incorporate structural information or contextual information or DEM spatial data, our approach seems to be similar or even 
Table 8 Error matrix of supervised classification using winter image

\begin{tabular}{|c|c|c|c|c|c|c|c|c|c|c|c|c|c|c|c|c|}
\hline & \multirow[t]{2}{*}{ Class ID } & \multicolumn{15}{|c|}{ Reference data } \\
\hline & & 1 & 2 & 3 & 4 & 5 & 6 & 7 & 8 & 9 & 10 & 11 & 12 & 13 & Total & U. Acc (\%) \\
\hline \multirow[t]{15}{*}{ Classified data } & 1 & 34 & 0 & 5 & 1 & 5 & 0 & 0 & 0 & 0 & 2 & 3 & 0 & 0 & 50 & 68 \\
\hline & 2 & 7 & 15 & 7 & 0 & 7 & 0 & 0 & 0 & 10 & 0 & 4 & 0 & 0 & 50 & 30 \\
\hline & 3 & 6 & 0 & 34 & 0 & 3 & 0 & 0 & 0 & 2 & 0 & 5 & 0 & 0 & 50 & 68 \\
\hline & 4 & 0 & 0 & 0 & 47 & 0 & 2 & 0 & 0 & 1 & 0 & 0 & 0 & 0 & 50 & 94 \\
\hline & 5 & 6 & 3 & 3 & 0 & 37 & 0 & 0 & 0 & 1 & 0 & 0 & 0 & 0 & 50 & 74 \\
\hline & 6 & 5 & 0 & 14 & 0 & 2 & 16 & 0 & 0 & 5 & 0 & 8 & 0 & 0 & 50 & 32 \\
\hline & 7 & 12 & 0 & 5 & 3 & 1 & 0 & 1 & 5 & 15 & 0 & 5 & 3 & 0 & 50 & 2 \\
\hline & 8 & 2 & 0 & 0 & 2 & 1 & 0 & 2 & 36 & 0 & 0 & 0 & 0 & 7 & 50 & 72 \\
\hline & 9 & 7 & 2 & 0 & 4 & 2 & 1 & 0 & 0 & 32 & 0 & 2 & 0 & 0 & 50 & 64 \\
\hline & 10 & 1 & 0 & 0 & 1 & 2 & 0 & 4 & 2 & 0 & 40 & 0 & 0 & 0 & 50 & 80 \\
\hline & 11 & 12 & 1 & 11 & 0 & 8 & 0 & 0 & 0 & 2 & 0 & 16 & 0 & 0 & 50 & 32 \\
\hline & 12 & 8 & 5 & 5 & 4 & 0 & 1 & 0 & 1 & 15 & 0 & 0 & 11 & 0 & 50 & 22 \\
\hline & 13 & 0 & 0 & 0 & 0 & 0 & 0 & 3 & 5 & 0 & 0 & 0 & 0 & 42 & 50 & 84 \\
\hline & Total & 100 & 26 & 84 & 62 & 68 & 20 & 10 & 49 & 83 & 42 & 43 & 14 & 49 & 650 & \\
\hline & P. Acc $(\%)$ & 34 & 58 & 40 & 76 & 54 & 80 & 10 & 73 & 39 & 95 & 37 & 79 & 86 & & \\
\hline
\end{tabular}

Overall classification accuracy $=0.55$; Kappa coefficient $=0.51$

$P$. Acc producer's accuracy, $U$. Acc user's accuracy, 1 pasture, 2 fruit trees, 3 cereals, 4 forest, 5 olive, 6 citrus, 7 rocky lands, 8 sabkha, 9 shrublands, 10 urban, 11 vegetables, 12 vineyard, 13 water

Table 9 Error matrix of supervised classification using multi-date images

\begin{tabular}{|c|c|c|c|c|c|c|c|c|c|c|c|c|c|c|c|c|}
\hline & \multirow[t]{2}{*}{ Class ID } & \multicolumn{15}{|c|}{ Reference data } \\
\hline & & 1 & 2 & 3 & 4 & 5 & 6 & 7 & 8 & 9 & 10 & 11 & 12 & 13 & Total & U. Acc $(\%)$ \\
\hline \multirow[t]{15}{*}{ Classified data } & 1 & 43 & 0 & 1 & 0 & 4 & 0 & 0 & 0 & 0 & 0 & 2 & 0 & 0 & 50 & 86 \\
\hline & 2 & 10 & 22 & 4 & 0 & 0 & 0 & 0 & 2 & 10 & 0 & 2 & 0 & 0 & 50 & 44 \\
\hline & 3 & 4 & 2 & 40 & 0 & 0 & 0 & 0 & 0 & 0 & 0 & 4 & 0 & 0 & 50 & 80 \\
\hline & 4 & 0 & 0 & 0 & 48 & 0 & 0 & 0 & 0 & 2 & 0 & 0 & 0 & 0 & 50 & 96 \\
\hline & 5 & 0 & 4 & 2 & 0 & 44 & 0 & 0 & 0 & 0 & 0 & 0 & 0 & 0 & 50 & 88 \\
\hline & 6 & 2 & 0 & 0 & 2 & 0 & 40 & 0 & 0 & 6 & 0 & 0 & 0 & 0 & 50 & 80 \\
\hline & 7 & 2 & 0 & 0 & 0 & 0 & 0 & 18 & 0 & 0 & 0 & 0 & 0 & 30 & 50 & 36 \\
\hline & 8 & 4 & 0 & 0 & 0 & 0 & 0 & 0 & 42 & 0 & 0 & 0 & 0 & 4 & 50 & 84 \\
\hline & 9 & 2 & 0 & 0 & 4 & 0 & 0 & 0 & 0 & 44 & 0 & 0 & 0 & 0 & 50 & 88 \\
\hline & 10 & 0 & 0 & 0 & 0 & 0 & 0 & 2 & 0 & 3 & 45 & 0 & 0 & 0 & 50 & 90 \\
\hline & 11 & 2 & 2 & 6 & 0 & 0 & 0 & 0 & 0 & 2 & 0 & 38 & 0 & 0 & 50 & 76 \\
\hline & 12 & 6 & 0 & 0 & 0 & 0 & 0 & 0 & 0 & 4 & 0 & 4 & 36 & 0 & 50 & 72 \\
\hline & 13 & 0 & 0 & 0 & 0 & 0 & 0 & 0 & 0 & 0 & 0 & 0 & 0 & 50 & 50 & 100 \\
\hline & Total & 75 & 30 & 53 & 54 & 48 & 40 & 20 & 44 & 71 & 45 & 50 & 36 & 84 & 650 & \\
\hline & P. Acc $(\%)$ & 57 & 73 & 75 & 89 & 92 & 100 & 90 & 95 & 62 & 100 & 76 & 100 & 60 & & \\
\hline
\end{tabular}

Overall classification accuracy $=0.78$; Kappa coefficient $=0.76$

$P$. Acc producer's accuracy, $U$. Acc user's accuracy, 1 pasture, 2 fruit trees, 3 cereals, 4 forest, 5 olive, 6 citrus, 7 rocky lands, 8 sabkha, 9 shrublands, 10 urban, 11 vegetables, 12 vineyard, 13 water

better in term of classification accuracy. Gong and Howarth [23] incorporated structural information into a conventional MLC and found that this approach improved the overall accuracy up to $86.1 \%$ compared with the conventional method (76.6\%). Integrating contextual information with per-pixel maximum likelihood classification 
Table 10 Error matrix of supervised classification using the proposed approach

\begin{tabular}{|c|c|c|c|c|c|c|c|c|c|c|c|c|c|c|c|c|}
\hline & \multirow[t]{2}{*}{ Class ID } & \multicolumn{15}{|c|}{ Reference data } \\
\hline & & 1 & 2 & 3 & 4 & 5 & 6 & 7 & 8 & 9 & 10 & 11 & 12 & 13 & Total & U. Acc (\%) \\
\hline \multirow[t]{15}{*}{ Classified data } & 1 & 44 & 0 & 2 & 0 & 0 & 0 & 0 & 1 & 0 & 0 & 3 & 0 & 0 & 50 & 88 \\
\hline & 2 & 5 & 36 & 0 & 0 & 5 & 2 & 0 & 0 & 2 & 0 & 0 & 0 & 0 & 50 & 72 \\
\hline & 3 & 2 & 0 & 45 & 0 & 3 & 0 & 0 & 0 & 0 & 0 & 0 & 0 & 0 & 50 & 90 \\
\hline & 4 & 0 & 0 & 0 & 49 & 0 & 0 & 0 & 0 & 1 & 0 & 0 & 0 & 0 & 50 & 98 \\
\hline & 5 & 0 & 3 & 0 & 0 & 45 & 0 & 0 & 0 & 1 & 0 & 0 & 1 & 0 & 50 & 90 \\
\hline & 6 & 0 & 0 & 0 & 2 & 0 & 46 & 0 & 0 & 2 & 0 & 0 & 0 & 0 & 50 & 92 \\
\hline & 7 & 2 & 0 & 0 & 0 & 0 & 0 & 25 & 0 & 0 & 3 & 0 & 0 & 20 & 50 & 50 \\
\hline & 8 & 0 & 0 & 0 & 0 & 0 & 0 & 0 & 49 & 0 & 0 & 0 & 0 & 1 & 50 & 98 \\
\hline & 9 & 2 & 0 & 0 & 1 & 0 & 0 & 0 & 0 & 47 & 0 & 0 & 0 & 0 & 50 & 94 \\
\hline & 10 & 0 & 0 & 0 & 0 & 0 & 0 & 2 & 2 & 0 & 46 & 0 & 0 & 0 & 50 & 92 \\
\hline & 11 & 3 & 0 & 5 & 0 & 0 & 0 & 0 & 0 & 2 & 0 & 40 & 0 & 0 & 50 & 80 \\
\hline & 12 & 4 & 3 & 0 & 0 & 1 & 0 & 0 & 0 & 4 & 0 & 0 & 38 & 0 & 50 & 76 \\
\hline & 13 & 0 & 0 & 0 & 0 & 0 & 0 & 0 & 0 & 0 & 0 & 0 & 0 & 50 & 50 & 100 \\
\hline & Total & 62 & 42 & 52 & 52 & 54 & 48 & 27 & 52 & 59 & 49 & 43 & 39 & 71 & 650 & \\
\hline & P. Acc $(\%)$ & 71 & 86 & 87 & 94 & 83 & 96 & 93 & 94 & 80 & 94 & 93 & 97 & 70 & & \\
\hline
\end{tabular}

Overall classification accuracy $=0.86$; Kappa Coefficient $=0.85$

$P$. Acc producer's accuracy, $U$. Acc user's accuracy, 1 pasture, 2 fruit trees, 3 cereals, 4 forest, 5 olive, 6 citrus, 7 rocky lands, 8 sabkha, 9 shrublands, 10 urban, 11 vegetables, 12 vineyard, 13 water

could be another way to improve the classification accuracy [72]. Lucas et al. [48] developed a classification approach covering multi-temporal satellite images; IACS land management unit data software (i.e., eCognition) that effectively combines fuzzy logic, rule-based classification and segmentation algorithms, and a DEM of sufficient spatial resolution. They found that this approach was able to map seminatural habitats and agricultural land cover with accuracies exceeding $80 \%$.

\section{Conclusion}

Accurate land cover map plays an important role for addressing recent environmental issues and agriculture challenges. In this study, we analyzed the possible use of single and multi-date images for land cover classification in a large cropland dominated area $\left(29,000 \mathrm{~km}^{2}\right)$. Furthermore, we developed a new approach to improve the classification accuracy. The proposed approach aimed at initially dividing the study area into three land use groups: inland water, croplands and other land use. Then, we classified each group using the MLC. Recent Landsat 8 images were used for monitoring the phenology of different land cover classes and developing the land cover map.

Regarding the temporal resolution of the input data, it was found that the use of single date satellite images in the supervised classification was not accurate for the discrimination between land cover types which have similar phenology trends. In that case, the overall accuracy did not exceed $55 \%$. Using the information of three images acquired in different seasons (spring, summer and winter), the classification accuracy was enhanced up to $78 \%$. These results corroborate other studies that recognized the benefits of using multi-seasonal satellite images for cropland mapping.

The proposed approach was found to outperform the conventional classification approaches in terms of classification accuracy. The classification accuracies of all land cover classes were improved and the overall accuracy reached $86 \%$. Furthermore, the Kappa coefficient was improved from 0.76 in the case of conventional supervised classification using multi-date images to 0.85 in the proposed approach. These results demonstrate the usefulness of dividing the study area into different land use groups depending on the phenology of crops in reducing the misclassification errors and improving the clarity and accuracy of the generated land cover map. The use of the generated thematic map for modeling environmental issues such as soil erosion can enhance the accuracy of model outputs.

The approach highlighted in this paper was limited to cropland dominated area. Its application in other regions is possible. However, it needs a good understanding of the study area. Data used in this approach were acquired in the same growing season because of the limited cloud-free 
images in Landsat database. This can affect the classification of specific croplands that follow crop rotation management practices. The use of satellite images acquired in different growing for calculating the NDVI_Change and fixing the threshold can help assess the crop rotation management practices in the study area.

Acknowledgments The authors are grateful to Kamel MAALOUL, translator and English professor for having proofread the manuscript. They want also to thank the anonymous reviewers for accepting to review this manuscript.

\section{Compliance with ethical standards}

Conflict of interest On behalf of all authors, the corresponding author states that there is no conflict of interest

\section{References}

1. Abou EL-Magd I, Tanton TW (2003) Improvements in land use mapping for irrigated agriculture from satellite sensor data using a multi-stage maximum likelihood classification. Int $\mathrm{J}$ Remote Sens 24(21):4197-4206. doi:10.1080/0143116031000139791

2. Alpin P, Atkinson PM, Curran PJ (1998) Fine spatial resolution simulated satellite sensor imagery for land cover mapping in the United Kingdom. Remote Sens Environ 68(3):206-216. doi:10. 1016/S0034-4257(98)00112-6

3. Baban SM, Wan Yusof K (2001) Mapping land use/cover distribution on a mountainous tropical island using remote sensing and GIS. Int J Remote Sens 22(10):1909-1918. doi:10.1080/ 01431160119220

4. Benediktsson JA, Swain PH, Ersoy OK (1990) Neutral network approaches versus statistical methods in classification of multisource remote sensing data. IEEE Trans Geosci Remote Sens 28(4):540-552. doi:10.1109/TGRS.1990.572944

5. Bhardwaj A, Joshi PK, Snehmani Sam L, Singh MK, Singh S, Kumar R (2015) Applicability of Landsat 8 data for characterizing glacier facies and supraglacial debris. Int J Appl Earth Obs Geoinf 38:51-64. doi:10.1016/j.jag.2014.12.011

6. Bradley BA, Mustard F (2008) Comparison of phenology trends land cover class: a case study in the Great Basin, USA. Glob Chang Biol 14:334-346. doi:10.1111/j.1365-2486.2007.01479.x

7. Brewster CC, Allen JC, Kopp DD (1999) IPM from space: using satellite imagery to construct regional crop maps for studying crop-insect interaction. Am Entomol 45:105-117. doi:10.1093/ ae/45.2.105

8. Brown JF, Loveland TR, Ohlen DO, Zhu Z (1999) The global land-cover characteristics database: the user's perspective. Photogramm Eng Remote Sens 65:1069-1074

9. Chen X, Vierling L, Deering D (2005) A simple and effective radiometric correction method to improve landscape change detection across sensors and across time. Remote Sens Environ 98:63-79. doi:10.1016/j.rse.2005.05.021

10. Chen PY, Di Luzio M, Arnold JG (2006) Spatial agreement between two land-cover data sets stratified by agricultural ecoregions. Int J Remote Sens 27(15):3223-3238. doi:10.1080/ 01431160600567803

11. Claire B, Yang Z, Mueller R, Craiga M (2011) Monitoring US agriculture: the US department of agriculture, national agricultural statistics service, cropland data layer program. Geocarto Int 26(5):341-358. doi:10.1080/10106049.2011.562309
12. Congalton RG (1991) A review of assessing the accuracy of classifications of remotely sensed data. Remote Sens Environ 37:35-46

13. Di Gregorio A (2005) Land cover classification system software, classification concepts and user manual, software version 2. FAO Environmental and natural resources. Series 8. FAO Publishing, Rome

14. Domac A, Suzen ML (2006) Integration of environmental variables with satellite images in regional scale vegetation classification. Int J Remote Sens 27(7):1329-1350. doi:10.1080/ 01431160500444806

15. Ehrlich D, Estes JE, Singh A (1994) Applications of NOAAAVHRR $1 \mathrm{~km}$ data for environmental monitoring. Int J Remote Sens 15(1):145-161. doi:10.1080/01431169408954056

16. ERDAS (1999) ERDAS field guide, 5th edn. ERDAS, Atlanta

17. Foody GM, Campbell NA, Trodd NM, Wood TF (1992) Derivation and applications of probabilistic measures of class membership from the maximum-likelihood classification. Photogramm Eng Remote Sens 58(9):1335-1341

18. Foody GM (1999) The continuum of classification fuzziness in thematic mapping. Photogramm Eng Remote Sens 65:443-451

19. Fritz S, See L, Rembold F (2010) Comparison of global and regional land cover maps with statistical information for the agricultural domain in Africa. Int $J$ Remote Sens 31(9):2237-2256. doi:10.1080/01431160902946598

20. Gitelson AA (2004) Wide dynamic range vegetation index for remote quantification of biophysical characteristics of vegetation. J Plant Physiol 161(2):165-173. doi:10.1078/0176-1617-01176

21. Glenn EP, Huete AR, Nagler PL, Nelson SG (2008) Relationship between remotely-sensed vegetation indices, canopy attributes and plant physiological processes: what vegetation indices can and cannot tell us about the landscape. Sensor 8:2136-2160. doi:10.3390/s8042136

22. Global Land Cover Network (2013) Global-derived national land cover databases for Africa. http://www.glcn.org/databases/lc_gcafrica_en.jsp. Updated on 2 October 2013. Accessed 31 March 2016

23. Gong P, Howarth PJ (1990) The use of structural information for improving land cover classification accuracies at rural-urban fringe. Photogramm Eng Remote Sens 56(1):67-73

24. Gong Z, Kawamura K, Ishikawa N, Goto M, Wulan T, Alateng D, Yin T, Ito Y (2015) MODIS normalized difference vegetation index (NDVI) and vegetation n phenology dynamics in the Inner Mongolia grassland. Solid Earth 6:1185-1194

25. Gonzalez RC, Woods RE (1992) Digital imaging processing. Addison-Wesley, Massachusetts

26. Guerschman JP, Paruelo JM, Di Bella C, Giallorenzi MC, Pacin F (2003) Land cover classification in Argentine Pampas using multi-temporal Landsat TM data. Int $J$ Remote Sens 24(17):3381-3402. doi:10.1080/0143116021000021288

27. Hansen MC, Defries RS, Townshend JRG, Sohlberg R (2000) Global land cover classification at $1 \mathrm{~km}$ spatial resolution using a classification tree approach. Int $\mathrm{J}$ Remote Sens 21(6-7):1331-1364. doi:10.1080/014311600210209

28. Hmimina G, Dufrene E, Pontailler JY, Delpierre N, Aubinet M, Caquet B, Grandcourt AD, Burban B, Flechard C, Granier A, Gross P, Heinesch B, Longdoz B, Moureaux C, Ourcival JM, Rambal S, Andre LS, Soudani K (2013) Evaluation of the potential of MODIS satellite data to predict vegetation phenology in different biomes: an investigation using ground-based NDVI measurement. Remote Sens Environ 132:145-158. doi:10.1016/j. rse.2013.01.010

29. Huang Z, Lees BG (2004) Combining non parametric models for multi-source predictive forest mapping. Photogramm Eng Remote Sens 4:415-425. doi:10.14358/PERS.70.4.415 
30. Huemmrich KF, Black TA, Jarvis PG, McCaughney JH, Hall FG (1999) High temporal resolution NDVI phenology from micrometeorological radiation sensors. J Geophys Res 104(D22):27935-27944. doi:10.1029/1999JD900164

31. Jeong SJ, Ho CH, Gim HJ, Brown ME (2011) Phenology shifts at start vs. end of growing season in temperate vegetation over the Northern Hemisphere for the period 1982-2008. Glob Chang Biol 17:2385-2399. doi:10.1111/j.1365-2486.2011.02397.x

32. Jewell N (1989) An evaluation of multi-date SPOT data for agriculture and land use mapping in the United Kingdom. Int $\mathbf{J}$ Remote Sens 10(6):939-951. doi:10.1080/01431168908903936

33. Johnson DE, Ben Ali MN, Borman MM (1989) Rangeland and Marginal Cereal Cropland in Central Tunisia. Rangelands 11(5):222-225

34. Justice CO, Townshend JRG, Holben BN, Tucker CJ (1985) Analysis of the phenology of global vegetation using meteorological satellite data. Int J Remote Sens 6(8):1271-1318. doi:10. 1080/01431168508948281

35. Kantakumar LN, Neelamsetti P (2015) Multi-temporal land use classification using hybrid approach. Egypt J Remote Sens Space Sci 18(2):289-295. doi:10.1016/j.ejrs.2015.09.003

36. Karlsen SR, Tolvanen A, Kubin E, Poikolainen J, Hogda KA, Johansen B, Danks FS, Aspholm P, Wielgolaski FE, Makarova O (2008) MODIS-NDVI-based mapping of the length of the growing season in northern Fennoscandia. Int $\mathbf{J}$ Appl Earth Obs 10(3):253-266. doi:10.1016/j.jag.2007.10.005

37. Keuchel J, Naumann S, Heiler M, Siegmund A (2003) Automatic land cover analysis for Tenerife by supervised classification using remotely sensed data. Remote Sens Environ 86:530-541. doi:10. 1016/S0034-4257(03)00130-5

38. Kremer P, DeLiberty TL (2011) Local food practices and growing potential: mapping the case of Philadelphia. Appl Geogr 31(4):1252-1261. doi:10.1016/j.apgeog.2011.01.007

39. Langley SK, Cheshire HM, Humes KS (2001) A comparison of single date and multi-temporal satellite image classifications in a semi-arid grassland. J Arid Environ 49:401-411. doi:10.1006/ jare.2000.0771

40. Lenney MP, Woodcock CE, Collins JB, Hamdi H (1996) The status of agricultural lands in Egypt: the use of multi-temporal NDVI features derived from Landsat TM. Remote Sens Environ 56(1):8-20. doi:10.1016/0034-4257(95)00152-2

41. Lillesand TM, Kiefer RW, Chipman JW (2008) Remote sensing and image interpretation. Wiley, New York

42. Liu JY, Zhuang DF, Luo D, Xiao XM (2003) Land-cover classification of China: integrated analysis of AVHRR imagery and geophysical data. Int J Remote Sens 24(12):2485-2500. doi:10. 1080/01431160110115582

43. Liu J, Liu M, Tian H, Zhuang D, Zhang Z, Zhang W, Tang X, Deng X (2005) Spatial and temporal patterns of China's cropland during 1990-2000: an analysis based on Landsat TN data. Remote Sens Environ 98(4):442-456. doi:10.1016/j.rse.2005.08. 012

44. Lloyd D (1990) A phenological classification of terrestrial vegetation cover using shortwave vegetation index imagery. Int $\mathbf{J}$ Remote Sens 11(12):2269-2279. doi:10.1080/ 01431169008955174

45. Lo CP, Choi J (2004) A hybrid approach to urban land use/cover mapping using Landsat 7 Enhanced Thematic Mapper Plus (ETM+) images. Int J Remote Sens 25:1687-2700. doi:10.1080/ 01431160310001618428

46. Lobell DB, Asner GP (2004) Cropland distributions from temporal unmixing of MODIS data. Remote Sens Environ 93(3):412-422. doi:10.1016/j.rse.2004.08.002

47. Lu D, Weng Q (2007) A survey of image classification methods and techniques for improving classification performance. Inter $\mathbf{J}$ Remote Sens 28(5):823-870. doi:10.1080/01431160600746456
48. Lucas R, Rowlands A, Brown A, Keyworth S, Bunting P (2007) Rule-based classification of multi-temporal satellite imagery for habitat and agricultural land cover mapping. ISPRS J Photogramm Remote Sens 62:165-185. doi:10.1016/j.isprsjprs.2007.03.003

49. Lunetta RS, Shao Y, Ediriwickrema J, Lyon JG (2010) Monitoring agricultural cropping patterns across the Laurentian Great Lakes Basin using MODIS-NDVI data. Int J Appl Earth Obs Geoinf 12(2):81-88. doi:10.1016/j.jag.2009.11.005

50. Mingwei Z, Qingbo Z, Zhongxin C, Jia L, Yong Z, Chongfa C (2008) Crop discrimination in Northern China with double cropping systems using Fourier analysis of time-series MODIS data. Int J Appl Earth Obs Geoinf 10(4):476-485. doi:10.1016/j. jag.2007.11.002

51. Moulin S, Kergoat L, Viovy N, Dedieu GG (1997) Global-scale assessment of vegetation phenology using NOAA/AVHRR satellite measurements. J Clim 10:1154-1170. doi:10.1175/15200442(1997)010<1154:GSAOVP > 2.0.CO;2

52. Myint SW, Gober P, Brazel A, Grossman-Clarke S, Weng Q (2011) Per-pixel vs. object-based classification of urban land cover extraction using high spatial resolution imagery. Remote Sens Environ 115:1145-1161. doi:10.1016/j.rse.2010.12.017

53. Oetter DR, Cohen WB, Berterretche M, Maiersperger TK, Kennedy RE (2000) Land cover mapping in an agricultural setting using multiseasonal Thematic Mapper data. Remote Sens Environ $76: 139-155$

54. Otukei JR, Blaschke T (2010) Land cover change assessment using decision trees vector machines and maximum likelihood classification algorithms. Int J Appl Earth Obs Geoinf 12(1):S27S31. doi:10.1016/j.jag.2009.11.002

55. Panigrahy S, Sharma SA (1997) Mapping of crop rotation using multi-date Indian remote sensing digital data. ISPRS J Photogramm Remote Sens 52:85-91. doi:10.1016/S09242716(97)83003-1

56. Pax-Lenney M, Woodcock CE (1997) Monitoring agricultural lands in Egypt with multitemporal Landsat TM imagery: how many images are needed? Remote Sens Environ 59:522-529

57. Powell RL, Matzke N, De Souza Jr C, Clark M, Numata I, Hess LL, Roberts DA (2004) Sources of error in accuracy assessment of thematic land-cover maps in the Brazilian Amazon. Remote Sens Environ 90:221-234. doi:10.1016/j.rse.2003.12.007

58. Reed BC, Brown JF, VenderZee D, Loveland TR, Merchant JW, Ohlen DO (1994) Measuring phenological variability from satellite imagery. J Veg Sci 5:703-714. doi:10.2307/3235884

59. Richards JA, Jia X (1999) Remote sensing digital image analysis. Springer, Berlin

60. Rogan J, Chen D (2004) Remote sensing technology for mapping and monitoring land-cover and land-use change. Prog Plan 61(4):301-325. doi:10.1016/S0305-9006(03)00066-7

61. Roumenina E, Atzberge C, Vassilev V, Dimitrov P, Kamenova I, Banov M, Filchev L, Jelev G (2015) Single and multi-date crop identification using PROBA-V 100 and $300 \mathrm{~m} \mathrm{S1}$ products on Zlatia test site, Bulgaria. Remote Sens 7:13843-13862. doi:10. 3390/rs71013843

62. Roy DP, Wulder MA, Loveland TR, Woodcock CE, Allen RG, Anderson MC et al (2014) Landsat-8: science and product vision for terrestrial global change research. Remote Sens Environ 145:154-172. doi:10.1016/j.rse.2014.02.001

63. Saadat H, Adamowski J, Bonnell R, Sharifi F, Namdar M, AleEbrahim S (2011) Iran use and land cover classification over a large area in Iran based on single date analysis of satellite imagery. ISPRS J Photogramm Remote Sens 66:608-619. doi:10. 1016/j.isprsjprs.2011.04.001

64. Sakamoto T, Yokozawa M, Toritani H, Shibayama M, Ishitsuka $\mathrm{N}$, Ohno H (2005) A crop phenology detection method using time-series MODIS data. Remote Sens Environ 96(3-4):366-374. doi:10.1016/j.rse.2005.03.008 
65. Sakamoto T, Nguyen NV, Ohno H, Ishitsuka N, Yokozawa M (2006) Spatio-temporal distribution of rice phenology and cropping systems in the Mekong Delta with special reference to the seasonal water flow of the Mekong and Bassac rivers. Remote Sens Environ 100:1-16. doi:10.1016/j.rse.2005.09.007

66. San Miguel-Ayanz J, Biging GS (1997) Comparison of singlestage and multi-stage classification approaches for cover type mapping with TM and SPOT data. Remote Sens Environ 59(1):92-104. doi:10.1016/S0034-4257(96)00109-5

67. Simoneaux V, Duchemin B, Helson D, Er-Raki S, Olioso A, Chehbouni AG (2008) The use of high resolution image time series for crop classification and evapotranspiration estimate over an irrigated area in central Morocco. Int $\mathbf{J}$ Remote Sens 29(1):95-116. doi:10.1080/01431160701250390

68. Simonetti E, Simonetti D, Preatoni D (2014) Phenology-based land cover classification using Landsat 8 time series, JRC Technical Reports. Publications of Office of the European Union, Luxembourg

69. Sohn Y, Rebello NS (2002) Supervised and unsupervised spectral angle classifiers. Photogramm Eng Remote Sens 68:1271-1280

70. Stevanov WL, Ramsey MS, Christensen PR (2001) Monitoring urban land cover change: an expert system approach to land cover classification of semi-arid to arid urban centers. Remote Sens Environ 77:173-185. doi:10.1016/S0034-4257(01)00204-8

71. Stuart N, Barratt T, Place C (2006) Classifying the Neotropical savannas of Belize using remote sensing and ground survey. J Biogeogr 33:476-490. doi:10.1111/j.1365-2699.2005.01436.x

72. Stuckens J, Coppin PR, Bauer ME (2000) Integrating contextual information with per-pixel classification for improved land cover classification. Remote Sens Environ 71(3):282-296. doi:10.1016/ S0034-4257(99)00083-8

73. Thapa RB, Murayama Y (2009) Urban mapping, accuracy, and image classification: a comparison of multiple approaches in Tsukuba City Japan. Appl Geogr 29:135-144. doi:10.1016/j. apgeog.2008.08.001

74. USGS (2015) Landsat missions: imaging the earth since 1972. http://landsat.usgs.gov/about_mission_history.php. Updated on 23 November 2015. Accessed 31 March 2016

75. USGS (2016) Landsat 8 (L8) data users handbook. Version 2.0. EROS, Sioux Falls, South Dakota. Accessible on line http:// landsat.usgs.gov/documents/Landsat8DataUsersHandbook.pdf

76. Vanhellemont Q, Ruddick K (2015) Advantages of high quality SWIR bands for ocean colour processing: examples from
Landsat-8. Remote Sens Environ 161:89-106. doi:10.1016/j.rse. 2015.02.007

77. Verbesselt J, Hyndman R, Zeileis A, Culvenor D (2010) Phenological change detection while accounting for abrupt and gradual trends in satellite image time series. Remote Sens Environ 114(12):2970-2980. doi:10.1016/j.rse.2010.08.003

78. Vuolo F, Richter K, Atzberger C (2011) Evaluation of time-series and phonological indicators for land cover classification based on MODIS data. In: Remote Sensing for Agriculture, Ecosystems, and Hydrology. SPIE Proceedings vol 8174. doi:10.1117/12.898389

79. Wardlow BD, Egbert SL, Kastens JH (2007) Analysis of timeseries MODIS $250 \mathrm{~m}$ vegetation index data for crop classification in the U.S. Central Great Plains. Remote Sens Environ 108(3):290-310. doi:10.1016/j.rse.2006.11.021

80. Wardlow BD, Egbert SL (2008) Large-area crop mapping using multi-series MODIS $250 \mathrm{~m}$ NDVI data: an assessment for the U.S. Central Great Plains. Remote Sens Environ 112(3):1096-1116. doi:10.1016/j.rse.2007.07.019

81. White MA, De Beurs KM, Didan K, Inouye DW, Richardson AD, Jensen OP et al (2009) Intercomparison, interpretation, and assessment of spring phenology in North America estimated from remote sensing for 1982-2006. Glob Chang Biol 15:2335-2359. doi:10.1111/j.1365-2486.2009.01910.x

82. Xie Y, Sha Z, Yu M (2008) Remote sensing imagery in vegetation mapping: a review. J Plant Ecol 1(1):9-23. doi:10.1093/jpe/ rtm005

83. Xin J, Yu Z, Leeuwen LV, Driessen PM (2002) Mapping crop key phenological stages in the North China Plain using NOAA time series images. Int J Appl Earth Obs Geoinf 4:109-117. doi:10.1016/S0303-2434(02)00007-7

84. Yang Y, Liu Y, Zhou M, Zhang S, Zhan W, Sun C, Duan Y (2015) Landsat 8 OLI image based terrestrial water extraction from heterogeneous backgrounds using a reflectance homogenization approach. Remote Sens Environ 171:14-32. doi:10. 1016/j.rse.2015.10.005

85. Yuan F, Sawaya KE, Loeffelholz BC, Bauer ME (2005) Land cover classification and change analysis of the Twin cities (Minnesota) Metropolitan area by multi-temporal Landsat remote sensing. Remote Sens Environ 98:317-328. doi:10.1016/j.rse. 2005.08.006

86. Zha Y, Gao J, Ni S (2003) Use of normalized difference built-up index in automatically mapping urban areas from TM imagery. Int J Remote Sens 24(3):583-594. doi:10.1080/01431160304987 